\section{(1) \\ CrossMark}

\title{
Risk factors for recurrent venous thromboembolism after unprovoked pulmonary embolism: the PADIS-PE randomised trial
}

\author{
Cécile Tromeur ${ }^{1,2}$, Olivier Sanchez ${ }^{2,3}$, Emilie Presles ${ }^{2,4}$, Gilles Pernod ${ }^{2,5}$, \\ Laurent Bertoletti ${ }^{2,6}$, Patrick Jego ${ }^{2,7}$, Elisabeth Duhamel ${ }^{2,8}$, Karine Provost ${ }^{9}$, \\ Florence Parent ${ }^{10}$, Philippe Robin ${ }^{2,11}$, Lucile Deloire ${ }^{12}$, Florent Leven ${ }^{13}$, \\ Fanny Mingant ${ }^{2,14}$, Luc Bressollette ${ }^{2,15}$, Pierre-Yves Le Roux ${ }^{2,11}$, \\ Pierre-Yves Salaun' ${ }^{2,11}$, Michel Nonent ${ }^{12}$, Brigitte Pan-Petesch ${ }^{2,16}$, \\ Benjamin Planquette ${ }^{2,3}$, Philippe Girard ${ }^{2,17}$, Karine Lacut ${ }^{1,2}$, Solen Melac ${ }^{1,2}$, \\ Patrick Mismetti ${ }^{2,6}$, Silvy Laporte ${ }^{2,4}$, Guy Meyer ${ }^{2,3}$, Dominique Mottier ${ }^{1,2}$, \\ Christophe Leroyer $^{1,2}$ and Francis Couturaud ${ }^{1,2}$ for the PADIS-PE Investigators ${ }^{18}$
}

@ERSpublications

Residual pulmonary embolism is an independent predictor for recurrence after unprovoked pulmonary embolism http://ow.ly/jf0X30fQQGf

Cite this article as: Tromeur C, Sanchez O, Presles E, et al. Risk factors for recurrent venous thromboembolism after unprovoked pulmonary embolism: the PADIS-PE randomised trial. Eur Respir J 2017; 51: 1701202 [https://doi.org/10.1183/13993003.01202-2017].

ABSTRACT We aimed to identify risk factors for recurrent venous thromboembolism (VTE) after unprovoked pulmonary embolism.

Analyses were based on the double-blind randomised PADIS-PE trial, which included 371 patients with a first unprovoked pulmonary embolism initially treated during 6 months who were randomised to receive an additional 18 months of warfarin or placebo and followed up for 2 years after study treatment discontinuation. All patients had ventilation/perfusion lung scan at inclusion (i.e. at 6 months of anticoagulation).

During a median follow-up of 41 months, recurrent VTE occurred in 67 out of 371 patients (6.8 events per 100 person-years). In main multivariate analysis, the hazard ratio for recurrence was 3.65 (95\% CI 1.33-9.99) for age 50-65 years, 4.70 (95\% CI 1.78-12.40) for age $>65$ years, 2.06 (95\% CI 1.14-3.72) for patients with pulmonary vascular obstruction index (PVOI) $\geqslant 5 \%$ at 6 months and 2.38 (95\% CI 1.154.89) for patients with antiphospholipid antibodies. When considering that PVOI at 6 months would not be available in practice, PVOI $\geqslant 40 \%$ at pulmonary embolism diagnosis (present in $40 \%$ of patients) was also associated with a 2 -fold increased risk of recurrence.

After a first unprovoked pulmonary embolism, age, PVOI at pulmonary embolism diagnosis or after 6 months of anticoagulation and antiphospholipid antibodies were found to be independent predictors for recurrence.

This article has supplementary material available from erj.ersjournals.com

Received: June 182017 | Accepted after revision: Oct 042017

Support statement: The study was supported by grants from the "Programme Hospitalier de Recherche Clinique" (French Dept of Health) and the sponsor was the University Hospital of Brest. The funding source was not involved in designing or conducting the study, collecting, managing, analysing or interpreting the data, preparing, reviewing or approving the manuscript, or deciding to submit this for publication. Funding information for this article has been deposited with the Crossref Funder Registry.

Conflict of interest: Disclosures can be found alongside this article at erj.ersjournals.com

Copyright @ERS 2017 
Affiliations: ${ }^{1}$ Dépt de Médecine Interne et Pneumologie, EA 3878, CIC INSERM 1412, Centre HospitaloUniversitaire de Brest, Université de Bretagne Occidentale, Brest, France. ${ }^{2}$ F-CRIN INNOVTE, Saint-Étienne, France. ${ }^{3}$ Université Paris Descartes, Université Sorbonne Paris Cité, Service de Pneumologie et de Soins Intensifs, Hôpital Européen Georges Pompidou, AP-HP, Université Paris Descartes, Sorbonne Paris Cité, INSERM UMR S 1140, Paris, France. "Unité de Recherche Clinique, Innovation et Pharmacologie, Centre Hospitalo-Universitaire de Saint-Étienne, INSERM U1059 SAINBIOSE, Université Jean Monnet, Saint-Étienne, France. ${ }^{5}$ Dépt de Médecine Vasculaire, Centre Hospitalo-Universitaire de Grenoble, Université de Grenoble 1, Grenoble, France. 'Service de Médecine Vasculaire et Thérapeutique, Unité de Pharmacologie Clinique, CIC1408, Centre Hospitalo-Universitaire de Saint-Étienne, INSERM U1059 SAINBIOSE, Université Jean Monnet, Saint-Étienne, France. ${ }^{7}$ Service de Médecine Interne, Centre Hospitalo-Universitaire de Rennes, Université de Rennes 1, Rennes, France. ${ }^{8}$ Service de Médecine Interne, Centre Hospitalier Général de SaintBrieuc, Saint-Brieuc, France. ${ }^{9}$ Service de Cardiologie, Centre Hospitalier Général de Lannion, Lannion, France. ${ }^{10}$ Service de Pneumologie, INSERM 999, Centre Hospitalo-Universitaire de Kremlin-Bicêtre, KremlinBicêtre, France. ${ }^{11}$ Service de Médecine Nucléaire, EA 3878, Centre Hospitalo-Universitaire de Brest, Université de Bretagne Occidentale, Brest, France. ${ }^{12}$ Service de Radiologie, EA 3878, CIC INSERM 1412, Centre Hospitalo-Universitaire de Brest, Université de Bretagne Occidentale, Brest, France. ${ }^{13}$ Service de Cardiologie, EA 4324, Centre Hospitalo-Universitaire de Brest, Université de Bretagne Occidentale, Brest, France. ${ }^{14}$ Service d'Hématologie Biologique, EA 3878, Centre Hospitalo-Universitaire de Brest, Université de Bretagne Occidentale, Brest, France. ${ }^{15}$ Service d'Echo-doppler Vasculaire, EA 3878, CIC INSERM 1412, Centre Hospitalo-Universitaire de Brest, Université de Bretagne Occidentale, Brest, France. ${ }^{16}$ Service de Médecine Interne, Centre Hospitalier Général de Quimper, Quimper, France. ${ }^{17}$ Dépt Thoracique, Institut Mutualiste Montsouris; Paris, France. ${ }^{18}$ Members of the PADIS-PE Study Group are listed in the Acknowledgements section.

Correspondence: Francis Couturaud, Dépt de Médecine Interne et Pneumologie, Hôpital de la Cavale Blanche, CHRU de Brest, 29609 Brest Cedex, France. E-mail: francis.couturaudachu-brest.fr

\section{Introduction}

After a first episode of unprovoked venous thromboembolism (VTE), extending anticoagulation beyond 3-6 months is associated with a major reduction in the risk of recurrence as long as treatment is continued, but this benefit is not maintained after treatment discontinuation $[1,2]$. These results support international guidelines that recommend indefinite anticoagulation in patients with a first unprovoked VTE and a low or moderate risk of bleeding $[3,4]$.

However, based on the long-term risk estimates of recurrence after unprovoked VTE, indefinite anticoagulation will benefit approximately one-third of patients and expose the remaining two-thirds to an unjustified risk of bleeding [1-7]. As a consequence, identifying risk factors of recurrent VTE remains a major issue in order to select low-risk groups in whom anticoagulation should not be extended and high-risk patients who require indefinite anticoagulation [8]. Several clinical, biochemical or morphological predictors of recurrence have been identified; however, for most of them, the strength of the association with recurrent VTE and their clinical impact were moderate or uncertain [3, 5, 9-17]. Such an issue is of particular importance when unprovoked VTE initially occurred as unprovoked pulmonary embolism because there is evidence that these patients will more likely develop recurrence as a new pulmonary embolism (i.e. in $\sim 80 \%$ of cases of recurrence) rather than deep vein thrombosis (DVT), which is associated with a higher case fatality rate $[2,18]$.

We previously published the results of the PADIS-PE (Prolonged Anticoagulation During 18 months versus placebo after Initial Six-month treatment for a first episode of idiopathic Pulmonary Embolism) study, a randomised, double-blind, trial comparing an additional 18 month of warfarin versus placebo in 371 patients initially treated during an uninterrupted 6-month period for a first unprovoked pulmonary embolism [2]. In this planned substudy, we aimed to identify predictors of recurrent VTE in this population.

\section{Methods}

\section{Study design and population}

The design and the main results of the PADIS-PE study have been previously described [2]. Briefly, consecutive patients aged $\geqslant 18$ years having experienced a first episode of a proven symptomatic unprovoked pulmonary embolism and having been treated initially for an uninterrupted 6-month period with a vitamin $\mathrm{K}$ antagonist were eligible [2]. Pulmonary embolism was unprovoked when occurring in the absence of any major reversible risk factor for VTE within 3 months before diagnosis (i.e. surgery with locoregional or general anaesthesia $>30 \mathrm{~min}$, trauma with or without plaster cast of the lower limbs and bed rest $>72 \mathrm{~h}$ ) and in the absence of active cancer or cancer resolved within <2 years prior to diagnosis [2]. All participants were enrolled in 14 French hospital centres from July 13, 2007 to March 15, 2012 [2]. The PADIS-PE study was registered at ClinicalTrials.gov with identifier number NCT00740883.

\section{Randomisation and interventions}

After an initial 6 months of anticoagulation, patients were included and randomised to either warfarin or placebo for 18 months [2]. After the end of the study treatment period, all patients were followed up for 
an additional median period of 24 months (supplementary figure S1) [2]. At the time of inclusion (i.e. after the initial 6 months of anticoagulation), all patients underwent centralised frozen blood samples, leg vein ultrasound, ventilation/perfusion (V/Q) lung scan and transthoracic echocardiography (TTE) according to a predefined methodology and before randomisation (supplementary figure S1) [2]. Centralised frozen blood plasmas were also taken at 1, 18, 19 and 42 months for all patients. After the last patient was followed up, thrombophilia testing was performed by biologists blinded from study treatment allocation and patients' characteristics [2], and all V/Q lung scans (at inclusion and at pulmonary embolism diagnosis) and spiral computed tomography pulmonary angiography (CTPA) at pulmonary embolism diagnosis were centrally re-interpreted by two independent readers, blinded from the study treatment allocation, the results of other imaging tests and the patients' characteristics.

\section{Outcome measures}

The primary outcome for this subanalysis study was symptomatic recurrent VTE, including objectively confirmed nonfatal symptomatic pulmonary embolism or proximal DVT or fatal VTE during follow-up after inclusion in the study $[2,19,20]$. All outcomes were adjudicated blindly by an independent central Clinical Events Committee [2].

The primary assessment of risk factors of symptomatic recurrent VTE was based on pre-specified and prospectively collected variables, including clinical, biochemical (i.e. thrombophilia and D-dimer level at inclusion) and imaging variables (residual DVT on leg ultrasound and pulmonary vascular obstruction index (PVOI) on V/Q lung scan at inclusion) (supplementary material) [2]. The secondary aim was to assess the impact of PVOI measured at the time of pulmonary embolism diagnosis, which was collected retrospectively.

\section{Imaging parameters}

Right ventricular dysfunction (RVD) was assessed using TTE at inclusion and using CTPA or TTE in the absence of CTPA at pulmonary embolism diagnosis. RVD was defined by 1) right ventricular/left ventricular diameter ratio $>1.0$ if measured on CTPA scan (right ventricular and left ventricular diameters were measured by identifying the maximum distance between ventricular endocardium and the interventricular septum perpendicular to the long axis) or $>0.9$ if measured on TTE (apical or subcostal four-chamber view), or 2) systolic pulmonary arterial pressure $>50 \mathrm{mmHg}$ estimated from tricuspid velocity on TTE [21].

PVOIs at pulmonary embolism diagnosis and at inclusion were calculated using scores that were validated and correlated with the Miller index [22]. For PVOI measured on V/Q lung scan, each perfusion scan was scored as described by MeYER et al. [23]; for PVOI measured on CTPA, each lung was scored as described by QANADLI et al. [24] (supplementary material).

Residual DVT was defined by failure to fully compress a proximal vein based on bilateral compression ultrasonography of the lower limbs [25].

\section{Laboratory assays}

Thrombophilia testing included Factor V Leiden, G20210A prothrombin gene variant, Factor VIII, antithrombin, anticardiolipin antibody assays and D-dimer levels. Testing was performed for all the patients from centralised frozen blood samples taken at day 0 , except for protein $\mathrm{C}$, protein $\mathrm{S}$ and lupus anticoagulant, which were measured from frozen plasmas taken at 1 month in the placebo group and 19 months in the warfarin group in order to obtain results in the absence of anticoagulation (supplementary material).

\section{Statistical methods}

All analyses were performed on all randomised patients. Consistent with the PADIS-PE study design, where baseline characteristics were collected at inclusion, the primary outcome was estimated during the follow-up after inclusion (i.e. study treatment period plus follow-up after study treatment discontinuation) [2].

Univariate analyses were performed to select predictive variables for the multivariate model, and to determine the association between each potential predictor and VTE recurrence. In univariate analysis, time-to-event outcome was estimated, for each predefined variable, using a Cox proportional hazard regression model with adjustment on study treatment allocation, which provided hazard ratios and corresponding 95\% confidence intervals. In multivariate analysis, variables were selected on the following basis: 1) p-value $<0.15$ in univariate analysis, 2) prevalence $>3 \%$ and 3) clinical relevance. Prior to the multivariate analysis, correlations and interactions were systematically searched between variables of interest. For continuous variables that were statistically significant, the discriminant power was determined 
by calculating the area under the curve (AUC) on receiver operating characteristic (ROC) curve analysis; the most discriminant cut-off was then determined by calculating the Youden index.

For the primary objective of the study, a multivariate model was performed including all the variables selected on the above criteria. Regarding the second objectives, additional multivariate models were performed: 1) in the case where V/Q lung scan at inclusion would not be available in current practice and where PVOI at the diagnosis of pulmonary embolism could be properly calculated (model 2), and 2) in the case where both PVOI at inclusion and at pulmonary embolism diagnosis would be available (model 3).

Based on hazard ratio estimates, a score was built from each of these multivariate models. Cut-off values were chosen for each score to discriminate low-, intermediate- and high-risk groups. The predictive accuracy was assessed for each score by calculating sensitivity, specificity, negative and positive predictive values, and their 95\% confidence intervals. Regarding internal validation, the Harrell C index, uncorrected and corrected after bootstrapping, was calculated for each score [26]. The bootstrapping procedure was repeated 500 times.

Lastly, predefined sensitivity analyses were performed: 1) using a multiple imputation model and 2) on a modified study population where primary outcome was estimated after anticoagulation was stopped (i.e. from inclusion in the placebo group and from anticoagulation discontinuation in the warfarin group). All tests were two sided and a p-value $<0.05$ was considered to be statistically significant. Statistical analyses were performed using SAS version 9.4 (SAS Institute, Cary, NC, USA).

\section{Results}

Of the 374 enrolled patients, three withdrew consent and refused inclusion of their data in the analysis, leaving 184 patients randomised to warfarin and 187 to placebo (371 in total) [2]. At inclusion, the median (interquartile range (IQR)) duration of initial anticoagulation in the entire cohort was 6.3 (6.06.7) months. After randomisation, the median (IQR) length of follow-up was 40.9 (29.3-41.3) months in the overall cohort (40.9 (29.2-41.3) and $40.9(29.3-41.3)$ months in the warfarin and placebo group, respectively).

\section{Characteristics of the study population}

Mean \pm SD age was $58.0 \pm 17.7$ years and 190 (51.2\%) patients were female. 55 females were on the oestrogen-containing pill and none were on substitutive hormonal therapy. Among persistent risk factors for VTE, chronic inflammatory disease was present in $12(3 \%)$ patients (rectocolitis in one patient; polyarthritis or Horton disease in 11 patients) and previous cancer in 14 (3.8\%) patients (supplementary table S1).

At the time of pulmonary embolism diagnosis, a proximal DVT was present in 112 out of 357 patients (31.4\%); RVD was present in 110 out of 305 patients (36.1\%). The mean \pm SD PVOI measured using CTPA in 284 patients and $V / Q$ lung scan in 87 patients was $35.0 \pm 23.9 \%$.

At inclusion, a nonfully compressible proximal vein was present in 61 out of 365 patients (16.7\%); RVD was present in 24 out of 269 patients (8.9\%). Mean \pm SD PVOI measured using V/Q lung scan in 356 patients was $8.7 \pm 13.6 \%$. Mean \pm SD D-dimer level while on anticoagulant therapy was $352 \pm 458 \mu \mathrm{g} \cdot \mathrm{L}^{-1}$.

Thrombophilia was present in 120 (34.3\%) patients. Elevated Factor VIII level (90th percentile) and Factor $\mathrm{V}$ Leiden were the most common minor thrombophilias ( $10 \%$ and $9.4 \%$ of patients, respectively). The presence of antiphospholipid antibodies (APLAs) was the most frequent major thrombophilia (9\% of patients with either lupus anticoagulant or anticardiolipin antibodies (99th percentile)); protein C, protein $\mathrm{S}$ and antithrombin deficiencies were found in six out of 362 patients $(1.7 \%)$.

\section{Outcome}

Symptomatic recurrent VTE occurred during follow-up in 67 patients (20.0\%; 6.8 events per 100 person-years). All events occurred in the absence of anticoagulation, 53 events (68.0\%) being unprovoked (i.e. no major nor minor transient risk factors and no cancer), 48 events (71.0\%) being nonfatal pulmonary embolism and four events being fatal pulmonary embolism.

\section{Primary assessment of predictors for recurrent VTE}

In univariate analysis, age, previous cancer resolved from $>2$ years before the inclusion, chronic inflammatory disease, residual DVT (at inclusion), APLAs and elevated Factor VIII were found to be associated with an increased risk of recurrent VTE. There was no impact of sex, abnormal D-dimer and, as previously reported [4], duration of anticoagulation on the risk of recurrence (table 1). RVD measured at the time of pulmonary embolism diagnosis was a significant predictor of recurrence but not RVD at inclusion. PVOI at inclusion as a continuous variable was associated with $+2 \%$ increased risk of recurrence 
for each additional percentage point of PVOI (HR 1.02, 95\% CI 1.00-1.03) (table 1). Based on ROC analysis (supplementary figure S2), the most discriminant value of PVOI was 5\% (AUC 0.62, 95\% CI $0.57-0.68$ ) and patients with PVOI at inclusion $\geqslant 5 \%$ had a 2 - to 3 -fold increased risk of recurrence (tables 1 and 2).

In the primary multivariate analysis (first multivariate model), age, APLAs and PVOI at inclusion $\geqslant 5 \%$ remained significant predictors of recurrent VTE; patients with at least one of these factors represented 95.4\% (63 patients) of all recurrences (table 3 ).

\section{Secondary assessments of predictors for recurrent VTE}

In univariate analysis, PVOI at pulmonary embolism diagnosis, as a continuous variable, was associated with $+2 \%$ increased risk of recurrent VTE for each additional percentage point of PVOI (HR 1.02, 95\% CI 1.01-1.04) (table 1). Based on ROC analysis (supplementary figure S3), the most discriminant value of PVOI at pulmonary embolism diagnosis was $40 \%$ (AUC $0.67,95 \%$ CI $0.61-0.73$ ) and patients with PVOI at diagnosis of pulmonary embolism $\geqslant 40 \%$ had a 3 -fold increased risk of recurrence (tables 1 and 2).

In the second multivariate model, in which PVOI at inclusion was excluded (table 3), age, APLAs and PVOI at pulmonary embolism diagnosis $\geqslant 40 \%$ remained significant predictors of recurrent VTE; patients with at least one of these factors represented $96.7 \%$ (64 patients) of all recurrences.

When taking in account both PVOI at inclusion and at pulmonary embolism diagnosis, we found a significant correlation between these two parameters $(\mathrm{r}=0.28 ; \mathrm{p}<0.0001)$ as well as a significant interaction ( $p=0.002$ for interaction test). We therefore combined these two parameters into one variable with two categories (table 2) and in the third multivariate model (table 3), age, APLAs and combined PVOI at diagnosis and at inclusion remained associated with a significant risk of recurrent VTE. Patients with at least one of these factors represented $95.4 \%$ (63 patients) of all recurrences.

\section{Prediction score for recurrent VTE}

A prediction score for recurrent VTE was derived from each multivariate model (table 4 and figure 1). All scores showed similar high sensitivity and negative predictive values; the proportions of patients classified at low risk of recurrent VTE (annual incidence rate $<2 \%$ per year) were $22.3 \%, 18.1 \%$ and $16.2 \%$ for the first, second and third score, respectively. In addition, all scores identified a subgroup at high risk of recurrent VTE (annual incidence rate $>12 \%$ per year), which represented $38.7 \%, 37.1 \%$ and $51.8 \%$ of patients for the first, second and third score, respectively.

\section{Sensitivity analyses}

Multiple imputation models or modified multivariate models performed in patients after stopping anticoagulation (i.e. after randomisation in the placebo group and at the end of the 18 months of anticoagulation in the warfarin group) confirmed our three major potential predictors of recurrent VTE (supplementary table S2).

\section{Discussion}

In this analysis based on 371 patients who experienced a first episode of unprovoked pulmonary embolism, we found that age, PVOI at the time of pulmonary embolism diagnosis and/or after 6 months of anticoagulation and APLAs were independent predictors of recurrent VTE during a median follow-up of 41 months. Depending on local radiological expertise and geographic accessibility to V/Q lung scan in clinical practice, we derived three predictive scores for recurrence, all showing high and similar sensitivity and negative predictive values, and allowing us to classify one-fifth of patients at low risk of recurrence (annual incidence rate $<2 \%$ per year).

One of the most striking findings is the observation, in the main and all secondary multivariate analyses (supplementary table S2), of a strong and independent impact of PVOI, either at 6 months of anticoagulation or at diagnosis of pulmonary embolism, on the risk of recurrent VTE. Consistent with previous prospective or retrospective studies where PVOI after the first months of anticoagulation was assessed using V/Q lung scan, we found that residual pulmonary vascular obstruction was present in about one-third of patients and was associated with an increased risk of recurrent VTE [17, 27-31]. In our study, ROC curve analysis yielded a 5\% PVOI threshold, which was lower than in previous studies and whose reproducibility might be questionable [17, 27]; however, a 5\% perfusion defect on $V / Q$ lung scan represents one segmental perfusion defect that is clinically relevant in the setting of suspected pulmonary embolism [32]. In studies that assessed residual pulmonary vascular obstruction using CTPA, no association between this parameter and the risk of recurrent VTE was observed [33, 34]; however, it has been shown that the accuracy of CTPA to detect residual pulmonary vascular obstruction is inferior to that of $V / Q$ lung scan [34]. At pulmonary embolism diagnosis, consistent with others, mean PVOI was 
TABLE 1 Risk factors of recurrent venous thromboembolism (VTE) in univariate analysis

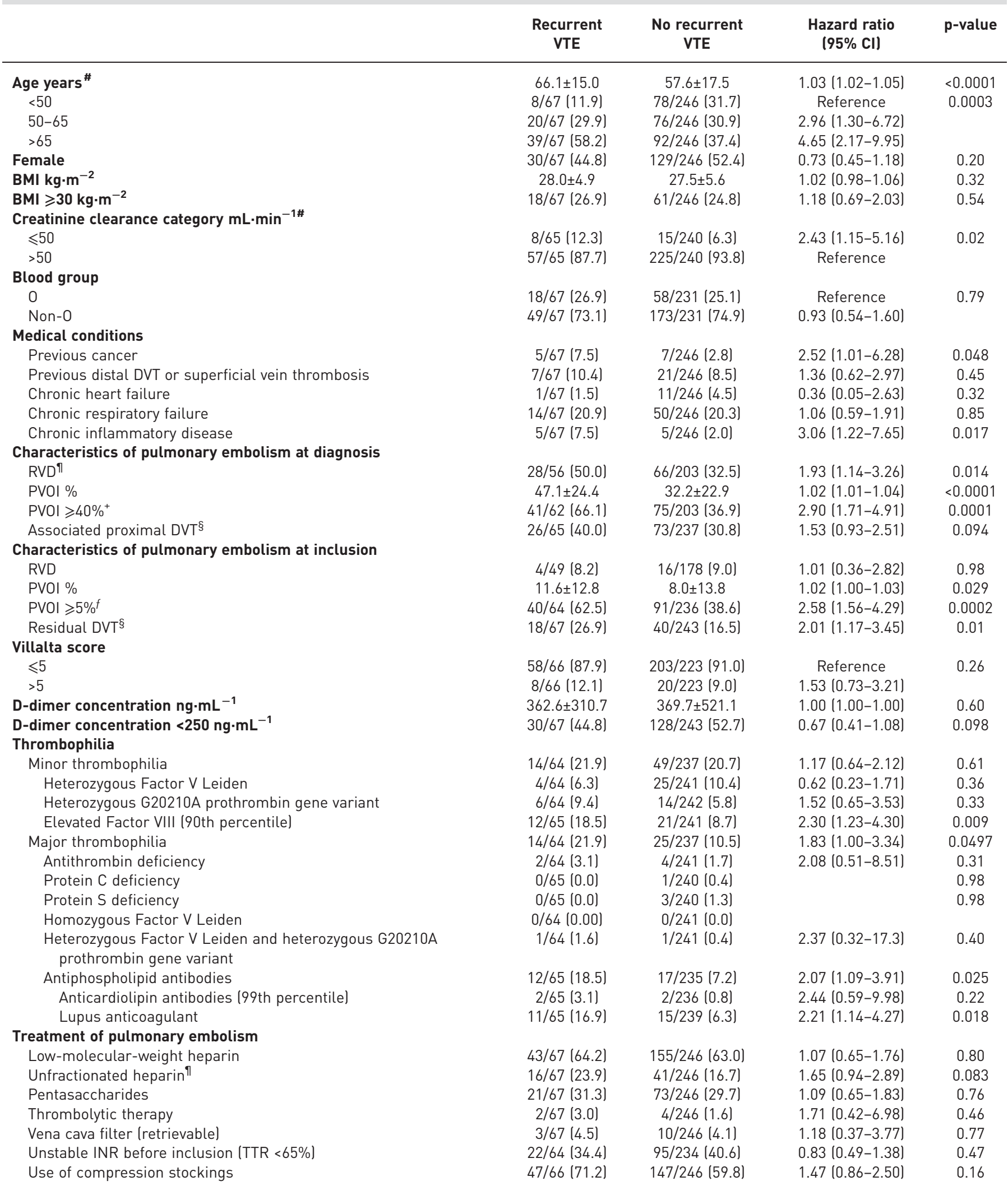


TABLE 1 Continued

\begin{tabular}{|c|c|c|c|c|}
\hline & $\begin{array}{l}\text { Recurrent } \\
\text { VTE }\end{array}$ & $\begin{array}{l}\text { No recurrent } \\
\text { VTE }\end{array}$ & $\begin{array}{l}\text { Hazard ratio } \\
(95 \% \mathrm{CI})\end{array}$ & p-value \\
\hline \multicolumn{5}{|c|}{$\begin{array}{l}\text { Concomitant treatment at the time of pulmonary embolism } \\
\text { diagnosis }\end{array}$} \\
\hline Antiplatelet agents & $4 / 67(6.0)$ & 22/246 (8.9) & $0.77(0.28-2.12)$ & 0.61 \\
\hline Statins & $17 / 67(25.4)$ & $50 / 246$ (20.3) & $1.50(0.86-2.60)$ & 0.15 \\
\hline Oestrogen contraceptive pill & $0 / 67(0.0)$ & $44 / 246(17.9)$ & & 0.98 \\
\hline \multicolumn{5}{|c|}{ 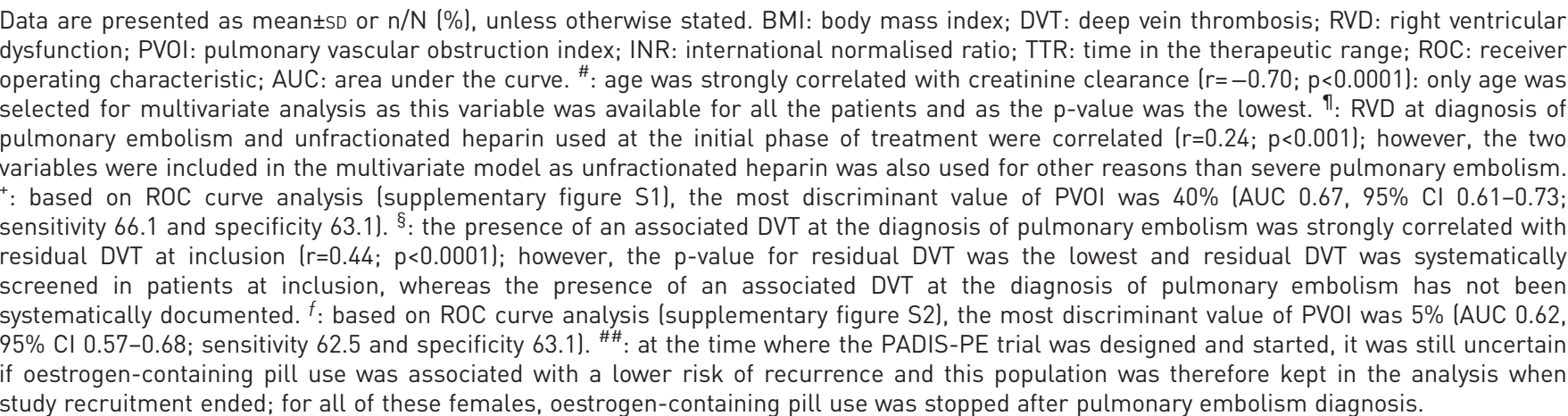 } \\
\hline
\end{tabular}

elevated (i.e. $35 \%)[28,30]$. In the only prospective trial that assessed the impact of this parameter on the risk of recurrent VTE after stopping anticoagulation, no association was observed between PVOI $\geqslant 10 \%$ at pulmonary embolism diagnosis (cut-off based on clinical relevance) and the risk of recurrent VTE [17]. In our study, ROC curve analysis yielded a $40 \%$ threshold PVOI value at diagnosis to predict a high risk of recurrent VTE, which is close to that observed in prospective trials that evaluated PVOI at pulmonary embolism diagnosis on the risk of death [35, 36] or early recurrent VTE during anticoagulation [37]. Consistent with the observation of a significant correlation between PVOI at pulmonary embolism diagnosis and PVOI at 6 months of anticoagulation, these parameters, when evaluated separately, were associated with an independent 2 -fold increased risk of recurrence without identifying predictors other than age and APLAs, and subsequent scores showed similar accuracy (tables 3 and 4). The combination of

TABLE 2 Pulmonary vascular obstruction index (PVOI) at inclusion and at pulmonary embolism diagnosis

\begin{tabular}{|c|c|c|c|c|c|}
\hline & Total & $\begin{array}{l}\text { Recurrent } \\
\text { VTE }\end{array}$ & $\begin{array}{c}\text { No recurrent } \\
\text { VTE }\end{array}$ & $\begin{array}{l}\text { Hazard ratio } \\
\text { (95\% CI) }\end{array}$ & p-value \\
\hline \multicolumn{6}{|l|}{ PVOI at inclusion ( $n=300)$} \\
\hline PVOI inclusion $\geqslant 5 \%$ & 131 & 40 (30.5) & 91 & $2.58(1.56-4.29)$ & 0.0002 \\
\hline \multicolumn{6}{|l|}{ PVOI at diagnosis $(n=265)$} \\
\hline PVOI diagnosis $<40 \%$ & 149 & $21(14.1)$ & 128 & Reference & 0.0001 \\
\hline PVOI diagnosis $<40 \%$ and PVOI inclusion $<5 \%$ & 96 & 8 (8.3) & 88 & Reference & \multirow[t]{4}{*}{0.0003} \\
\hline PVOI diagnosis $<40 \%$ and PVOI inclusion $\geqslant 5 \%$ & 51 & $13(25.4)$ & 38 & $3.85(1.59-9.30)$ & \\
\hline PVOI diagnosis $\geqslant 40 \%$ and PVOI inclusion $<5 \%$ & 46 & $17(37.0)$ & 29 & $5.35(2.31-12.40)$ & \\
\hline PVOI diagnosis $\geqslant 40 \%$ and PVOI inclusion $\geqslant 5 \%$ & 70 & $24(34.3)$ & 46 & $5.29(2.37-11.8)$ & \\
\hline \multicolumn{6}{|c|}{ Combined PVOI at diagnosis and at inclusion in two categories $(n=263)^{\pi}$} \\
\hline PVOI diagnosis $<40 \%$ and PVOI inclusion $<5 \%$ & 96 & $8(8.3)$ & 88 & Reference & $<0.0001$ \\
\hline
\end{tabular}


TABLE 3 Risk of recurrent venous thromboembolism in multivariate analyses

\begin{tabular}{|c|c|c|c|c|c|c|c|c|c|}
\hline Variables & \multicolumn{3}{|c|}{ Main multivariate model ${ }^{\#}$} & \multicolumn{3}{|c|}{ Second multivariate model ${ }^{\pi}$} & \multicolumn{3}{|c|}{ Third multivariate model ${ }^{+}$} \\
\hline \multicolumn{10}{|l|}{ Age years } \\
\hline$<50$ & Reference & 0.008 & & Reference & 0.007 & & Reference & 0.02 & \\
\hline $50-65$ & $3.65(1.33-9.99)$ & & +2 & $2.95(1.07-8.14)$ & & +2 & $2.80(1.01-7.75)$ & & +2 \\
\hline$>65$ & $4.70(1.78-12.4)$ & & +3 & $4.49(1.73-11.70)$ & & +3 & $3.73(1.43-9.77)$ & & +3 \\
\hline $\begin{array}{l}\text { Chronic } \\
\quad \text { inflammatory disease }\end{array}$ & $2.03(0.69-5.94)$ & 0.20 & & $1.95(0.66-5.73)$ & 0.23 & & $2.05(0.70-5.99)$ & 0.19 & \\
\hline Unfractionated heparin & $1.58(0.84-2.98)$ & 0.15 & & $1.29(0.65-2.57)$ & 0.47 & & $1.23(0.63-2.39)$ & 0.54 & \\
\hline RVD at diagnosis & $1.08(0.59-1.96)$ & 0.81 & & $0.86(0.46-1.62)$ & 0.65 & & $0.87(0.48-1.59)$ & 0.66 & \\
\hline \multicolumn{10}{|c|}{ PVOI } \\
\hline $\begin{array}{l}\text { Model 1: PVOI at } \\
\text { inclusion } \geqslant 5 \% \text { (over } \\
\text { PVOI at inclusion }<5 \% \text { ) }\end{array}$ & $2.06(1.14-3.72)$ & 0.016 & +2 & & & & & & \\
\hline $\begin{array}{l}\text { Model 3: PVOI at } \\
\text { diagnosis } \geqslant 40 \% \text { and/or } \\
\text { PVOI at inclusion } \geqslant 5 \% \\
\text { lover PVOI at diagnosis } \\
<40 \% \text { and PVOI at } \\
\text { inclusion }<5 \%)^{+}\end{array}$ & & & & & & & $4.73(1.99-11.2)$ & 0.0004 & +3 \\
\hline Residual DVT at inclusion & $1.72(0.92-3.23)$ & 0.09 & & $1.60(0.85-3.01)$ & 0.14 & & $1.70(0.90-3.22)$ & 0.10 & \\
\hline $\mathrm{D}$-dimer $<250 \mu \mathrm{g} \cdot \mathrm{L}^{-1}$ & $1.49(0.79-2.80)$ & 0.21 & & $1.53(0.81-2.88)$ & 0.19 & & $1.74(0.92-3.28)$ & 0.09 & \\
\hline $\begin{array}{l}\text { Antiphospholipid } \\
\text { antibodies (lupus } \\
\text { anticoagulant and/or } \\
\text { anticardiolipin } \\
\text { antibodies) }\end{array}$ & $2.38(1.15-4.89)$ & 0.01 & +2 & $2.64(1.32-5.28)$ & 0.006 & +2 & $2.57(1.29-5.11)$ & 0.007 & +2 \\
\hline
\end{tabular}

RVD: right ventricular dysfunction; PVOI: pulmonary vascular obstruction index; DVT: deep vein thrombosis. * main model: estimate of PVOI at pulmonary embolism diagnosis was not included (Harrell's C index including three significant variables was 0.66 lobserved score) and 0.68 after bootstrapping); ๆ: second model: estimate of PVOI at inclusion was excluded (Harrell's C index including three significant variables was 0.66 (observed score) and 0.68 after bootstrapping): ${ }^{+}$: third model: PVOI at pulmonary embolism diagnosis and at inclusion were combined into one variable with two categories (Harrell's $\mathrm{C}$ index including three significant variables was 0.63 (observed score) and 0.65 after bootstrapping).

these two PVOI into one variable added little to discriminate between patients at a low or high risk of recurrence (tables 3 and 4). In practice, if V/Q lung scan is not available, scoring PVOI at pulmonary embolism diagnosis based on CTPA requires local expertise and should be performed at distance from the acute episode; if available, V/Q lung scan should be performed at $\geqslant 3$ months [4].

Consistent with other studies in patients with unprovoked VTE, age and the presence of APLAs were associated with an increased risk of recurrent VTE $[5,8,15,16]$. Our high frequency of positive lupus anticoagulant might appear surprising and one could argue that such patients should have been excluded from the PADIS-PE trial. However, systematic screening for thrombophilia was not required to be eligible in our study and our high frequency of APLAs is consistent with other studies on unprovoked VTE where systematic detection of APLAs was not required [15]. Even after exclusion of patients with APLAs, the results remained unchanged (supplementary table S2E). Conversely, the risk of recurrent VTE in females was not lower than that in males, despite the inclusion of females who had an initial pulmonary embolism associated with oestrogen-containing pill use (supplementary table S1). If the lack of power is plausible, however, it has been shown that this risk estimate is lower in randomised trials compared with prospective cohorts [9]. Lastly, similarly to others [11], low D-dimer concentration (i.e. $<250 \mu \mathrm{g} \cdot \mathrm{mL}^{-1}$ while on anticoagulation) was also not associated with a lower risk of recurrence. 
TABLE 4 Accuracy of prediction scores

\begin{tabular}{|c|c|c|c|c|c|c|c|c|c|}
\hline Score values & $\begin{array}{l}\text { Recurrent } \\
\text { VTE }\end{array}$ & $\begin{array}{l}\text { No recurrent } \\
\text { VTE }\end{array}$ & $\begin{array}{l}\text { Hazard ratio } \\
(95 \% \mathrm{CI})\end{array}$ & $\begin{array}{l}\text { Annual incidence } \\
\text { per } 100 \text { person-years }\end{array}$ & $\begin{array}{l}\text { Comparisons between } \\
\text { classes for accuracy }\end{array}$ & $\begin{array}{l}\text { Sensitivity } \\
(95 \% \mathrm{Cl})\end{array}$ & $\begin{array}{l}\text { NPV } \\
(95 \% \mathrm{Cl})\end{array}$ & $\begin{array}{l}\text { Specificity } \\
(95 \% \mathrm{CI})\end{array}$ & $\begin{array}{c}\text { PPV } \\
(95 \% \mathrm{Cl})\end{array}$ \\
\hline Model $1 \pi$ & $n=62$ & $n=227$ & & & & & & & \\
\hline 0 & $3(5.7)$ & 50 & Reference & $\begin{array}{c}1.29 \\
(0.00-2.74)\end{array}$ & & & & & \\
\hline 2 & $12(16.2)$ & 62 & $\begin{array}{c}3.49 \\
(0.98-12.4)\end{array}$ & $\begin{array}{c}4.86 \\
(2.12-7.60)\end{array}$ & & & & & \\
\hline 3 & $8(19.0)$ & 34 & $\begin{array}{c}4.27 \\
(1.13-16.1)\end{array}$ & $\begin{array}{c}6.21 \\
(1.92-10.50)\end{array}$ & & & & & \\
\hline 4 & $10(25.6)$ & 29 & $\begin{array}{c}6.27 \\
(1.73-22.8)\end{array}$ & $\begin{array}{c}9.17 \\
(3.49-14.85)\end{array}$ & & & & & \\
\hline 5 & $21(30.0)$ & 49 & $\begin{array}{c}7.75 \\
(2.31-26.0)\end{array}$ & $\begin{array}{c}11.85 \\
(6.77-16.93)\end{array}$ & & & & & \\
\hline 6 & $1(50.0)$ & 1 & $\begin{array}{c}8.44 \\
(0.88-81.2)\end{array}$ & $\begin{array}{c}15.28 \\
(0.00-45.23)\end{array}$ & & & & & \\
\hline 7 & 7 (77.8) & 2 & $\begin{array}{c}27.9 \\
(7.19-108)\end{array}$ & $\begin{array}{c}67.85 \\
(17.58-118.1)\end{array}$ & & & & & \\
\hline \multicolumn{10}{|l|}{ Combination } \\
\hline Low risk 0 & 3 & 50 & Reference & $\begin{array}{c}1.29 \\
(0.00-2.74)\end{array}$ & & & & & \\
\hline $\begin{array}{l}\text { Intermediate } \\
\text { risk 2-3 }\end{array}$ & 20 & 96 & $\begin{array}{c}3.77 \\
(1.12-12.7)\end{array}$ & $\begin{array}{c}5.32 \\
(2.99-7.65)\end{array}$ & $\begin{array}{c}\text { Score } \\
0 \text { versus } \geqslant 2\end{array}$ & $\begin{array}{c}95.2 \\
(86.5-99.0)\end{array}$ & $\begin{array}{c}94.3 \\
(84.3-98.8)\end{array}$ & $\begin{array}{c}22.0 \\
(16.8-28.0)\end{array}$ & $\begin{array}{c}25.0 \\
(19.6-31.0)\end{array}$ \\
\hline High risk 4-7 & 39 & 81 & $\begin{array}{c}8.34 \\
(2.58-27.0)\end{array}$ & $\begin{array}{c}12.86 \\
(8.82-16.90)\end{array}$ & $\begin{array}{c}\text { Score } \\
\leqslant 3 \text { versus }>3\end{array}$ & $\begin{array}{c}62.9 \\
(49.7-74.8)\end{array}$ & $\begin{array}{c}86.4 \\
(80.3-91.2)\end{array}$ & $\begin{array}{c}64.3 \\
(57.7-70.5)\end{array}$ & $\begin{array}{c}32.5 \\
(24.2-41.6)\end{array}$ \\
\hline Model $2^{+}$ & $n=60$ & $n=197$ & & & & & & & \\
\hline 0 & $2(5.6)$ & 34 & Reference & $\begin{array}{c}1.23 \\
(0.00-2.94)\end{array}$ & & & & & \\
\hline 2 & $13(18.3)$ & 58 & $\begin{array}{c}4.32 \\
(0.97-19.1)\end{array}$ & $\begin{array}{c}5.86 \\
(2.67-9.05)\end{array}$ & & & & & \\
\hline 3 & $7(14.3)$ & 42 & $\begin{array}{c}3.46 \\
(0.72-16.7)\end{array}$ & $\begin{array}{c}4.59 \\
(1.20-7.98)\end{array}$ & & & & & \\
\hline 4 & $9(28.1)$ & 23 & $\begin{array}{c}6.85 \\
(1.48-31.7)\end{array}$ & $\begin{array}{c}10.17 \\
(3.53-16.81)\end{array}$ & & & & & \\
\hline 5 & $21(36.8)$ & 36 & $\begin{array}{c}9.78 \\
(2.29-41.7)\end{array}$ & $\begin{array}{c}15.64 \\
(8.96-22.32)\end{array}$ & & & & & \\
\hline 6 & 0 & 3 & & 0 & & & & & \\
\hline 7 & $8(88.9)$ & 1 & $\begin{array}{c}52.6 \\
(11.2-248.7)\end{array}$ & $\begin{array}{c}211.2 \\
(64.85-357.6)\end{array}$ & & & & & \\
\hline \multicolumn{10}{|l|}{ Combination } \\
\hline Low risk 0 & 2 & 34 & Reference & $\begin{array}{c}1.23 \\
(0.00-2.94)\end{array}$ & & & & & \\
\hline $\begin{array}{l}\text { Intermediate } \\
\text { risk 2-3 }\end{array}$ & 20 & 100 & $\begin{array}{c}3.98 \\
(0.93-17.0)\end{array}$ & $\begin{array}{c}5.34 \\
(3.01-7.67)\end{array}$ & $\begin{array}{c}\text { Score } \\
0 \text { versus } \geqslant 2\end{array}$ & $\begin{array}{c}96.7 \\
(88.5-99.6)\end{array}$ & $\begin{array}{c}94.4 \\
(81.3-99.3)\end{array}$ & $\begin{array}{c}17.3 \\
(12.3-23.3)\end{array}$ & $\begin{array}{c}26.2 \\
(20.6-32.6)\end{array}$ \\
\hline High risk 4-7 & 38 & 63 & $\begin{array}{c}10.00 \\
(2.42-41.6)\end{array}$ & $\begin{array}{c}15.85 \\
(10.81-20.89)\end{array}$ & $\begin{array}{c}\text { Score } \\
\leqslant 3 \text { versus }>3\end{array}$ & $\begin{array}{c}63.3 \\
(49.9-75.4)\end{array}$ & $\begin{array}{c}85.9 \\
(79.4-90.9)\end{array}$ & $\begin{array}{c}68.0 \\
(61.0-74.5)\end{array}$ & $\begin{array}{c}37.6 \\
(28.2-47.8)\end{array}$ \\
\hline
\end{tabular}




\begin{tabular}{|c|c|c|c|c|c|c|c|c|c|}
\hline Score values & $\begin{array}{l}\text { Recurrent } \\
\text { VTE }^{\#}\end{array}$ & $\begin{array}{l}\text { No recurrent } \\
\text { VTE }\end{array}$ & $\begin{array}{l}\text { Hazard ratio } \\
\text { (95\% CI) }\end{array}$ & $\begin{array}{l}\text { Annual incidence } \\
\text { per } 100 \text { person-years }\end{array}$ & $\begin{array}{l}\text { Comparisons between } \\
\text { classes for accuracy }\end{array}$ & $\begin{array}{l}\text { Sensitivity } \\
\text { (95\% CI) }\end{array}$ & $\begin{array}{c}\text { NPV } \\
(95 \% \mathrm{Cl})\end{array}$ & $\begin{array}{l}\text { Specificity } \\
(95 \% \mathrm{CI})\end{array}$ & $\begin{array}{c}\text { PPV } \\
(95 \% \mathrm{CI})\end{array}$ \\
\hline Model $3^{\S}$ & $n=60$ & $n=195$ & & & & & & & \\
\hline 0 & $2(6.4)$ & 29 & Reference & $\begin{array}{c}1.39 \\
(0.00-3.33)\end{array}$ & & & & & \\
\hline 2 & $4(9.8)$ & 37 & $\begin{array}{c}2.03 \\
(0.37-11.1)\end{array}$ & $\begin{array}{c}3.07 \\
(0.05-6.09)\end{array}$ & & & & & \\
\hline 3 & $5(12.2)$ & 36 & $\begin{array}{c}2.26 \\
(0.44-11.6)\end{array}$ & $\begin{array}{c}3.38 \\
(0.42-6.34)\end{array}$ & & & & & \\
\hline 4 & $0(0)$ & 2 & & 0 & & & & & \\
\hline 5 & $17(30.4)$ & 39 & $\begin{array}{c}6.80 \\
(1.57-29.4)\end{array}$ & $\begin{array}{c}11.57 \\
(6.06-17.08)\end{array}$ & & & & & \\
\hline 6 & 22 (31.9) & 47 & $\begin{array}{c}7.38 \\
(1.73-31.4)\end{array}$ & $\begin{array}{c}12.76 \\
(7.43-18.09)\end{array}$ & & & & & \\
\hline 7 & $3(45.9)$ & 4 & $\begin{array}{c}10.3 \\
(1.72-61.6)\end{array}$ & $\begin{array}{c}17.79 \\
(0.00-37.92)\end{array}$ & & & & & \\
\hline 8 & 7 (87.5) & 1 & $\begin{array}{c}31.5 \\
(6.53-152.00)\end{array}$ & $\begin{array}{c}102.2 \\
(26.51-178.00)\end{array}$ & & & & & \\
\hline \multicolumn{10}{|l|}{ Combination } \\
\hline Low risk 0 & 2 & 31 & Reference & $\begin{array}{c}1.39 \\
(0.00-3.33)\end{array}$ & & & & & \\
\hline $\begin{array}{l}\text { Intermediate } \\
\text { risk 2-4 }\end{array}$ & 12 & 84 & $\begin{array}{c}2.11 \\
(0.45-9.75)\end{array}$ & $\begin{array}{c}3.16 \\
(1.10-5.22)\end{array}$ & $\begin{array}{c}\text { Score } \\
0 \text { versus } \geqslant 2\end{array}$ & $\begin{array}{c}96.7 \\
(88.5-99.6)\end{array}$ & $\begin{array}{c}93.5 \\
(78.6-99.2)\end{array}$ & $\begin{array}{c}14.9 \\
(10.2-20.7)\end{array}$ & $\begin{array}{c}25.9 \\
(20.3-32.1)\end{array}$ \\
\hline High risk 5-8 & 46 & 80 & $\begin{array}{c}8.17 \\
(1.99-33.6)\end{array}$ & $\begin{array}{c}14.28 \\
(10.28-18.28)\end{array}$ & $\begin{array}{c}\text { Score } \\
\leqslant 4 \text { versus }>4\end{array}$ & $\begin{array}{c}81.7 \\
(71.9-91.5)\end{array}$ & $\begin{array}{c}90.4 \\
(83.5-95.1)\end{array}$ & $\begin{array}{c}53.3 \\
(46.1-60.5)\end{array}$ & $\begin{array}{c}35.0 \\
(27.1-43.5)\end{array}$ \\
\hline
\end{tabular}

Data are presented as $\mathrm{n}(\%)$ or $n$, unless otherwise stated. VTE: venous thromboembolic disease; NPV: negative predictive value; PPV: positive predictive value. ${ }^{\#}$ : percentages per strata; ${ }^{\text {I: }}$ main model: PVOI at diagnosis of pulmonary embolism was not included in the model; ${ }^{+}$: second model: PVOI at inclusion was not included in the model; ${ }^{\S}$ : third model: given the interaction between PVOI at diagnosis of pulmonary embolism and at inclusion, these variables were combined into one variable with two categories. 
a)

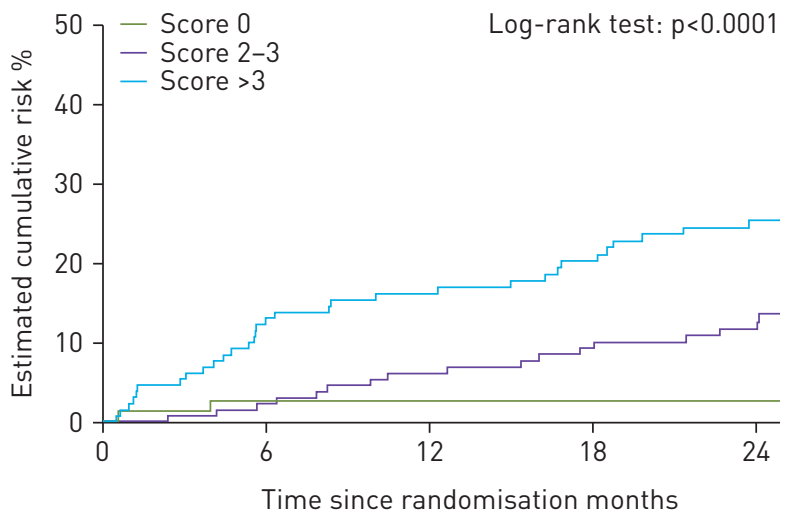

At risk $n$

Score 0

Score 2-3 133

Score $>3 \quad 132$

c)

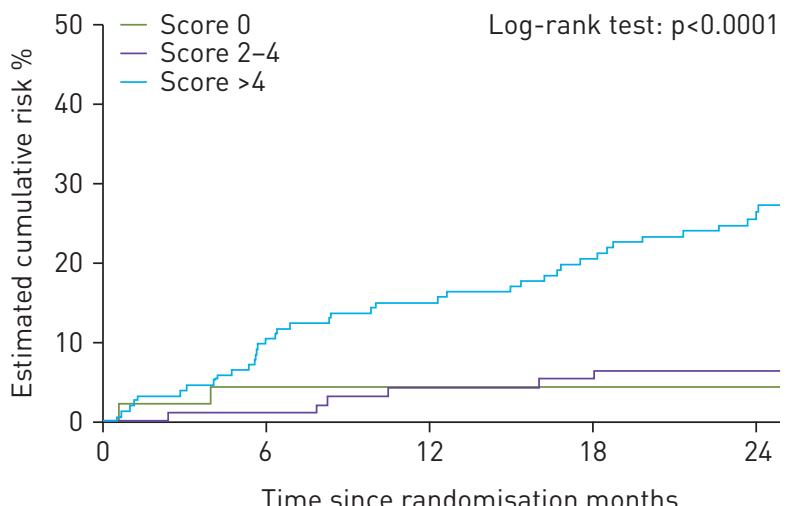

At risk $n$

$\begin{array}{lccccc}\text { Score } 0 & 47 & 44 & 43 & 38 & 27 \\ \text { Score 2-4 } & 95 & 94 & 89 & 84 & 65 \\ \text { Score }>4 & 154 & 137 & 126 & 111 & 71\end{array}$

b)

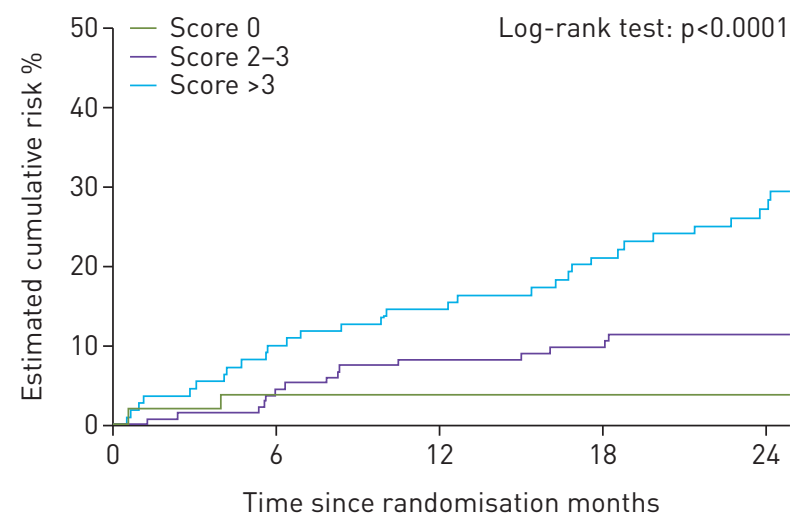

At risk $n$

$\begin{array}{lccccc}\text { Score } 0 & 53 & 50 & 49 & 41 & 30 \\ \text { Score 2-3 } & 134 & 128 & 118 & 112 & 79 \\ \text { Score }>3 & 111 & 99 & 92 & 80 & 54\end{array}$

FIGURE 1 Kaplan-Meier estimates of the probability of the outcome of recurrent venous thromboembolism during follow-up after stopping anticoagulation, according to score values: a) when pulmonary vascular obstruction index (PVOI) measured at pulmonary embolism diagnosis was excluded from the model, b) when PVOI measured at inclusion was excluded from the model, and c) when PVOI measured at diagnosis of pulmonary embolism and at inclusion were combined in a single variable.

Similarly to others $[8,38,39]$, our three derived scores showed high sensitivity and negative predictive values. The annual incidence rate of recurrent VTE was $<5 \%$ per year in the low-risk group, suggesting that anticoagulation should be stopped after 6 months; in contrast, the annual incidence rate of recurrence was $\geqslant 10 \%$ per year in the high-risk group (which is 4 -fold higher than the risk of major bleeding in the PADIS-PE trial and others), suggesting that anticoagulation should be continued, at least in patients with a low or moderate risk of bleeding (table 4) [3, 4]. In previous scores, most of them included at least age, sex and D-dimer, none of them were derived from cohorts with only pulmonary embolism patients, and PVOI for pulmonary embolism patients and APLAs were not available $[8,38,39]$. In our study, all the components of these previous scores were available and evaluated in univariate analysis, and, except for age, none of them was significantly associated with an increased risk of recurrent VTE. Thus, if PVOI and APLAs have the potential to provide additional information to these existing scores, this issue deserves further analyses.

Strengths of our study include: 1) a carefully predefined and characterised population (in terms of clinical, morphological and biochemical data) that was included in a double-blind randomised trial; 2) a minimal loss to follow-up; 3) a long follow-up period of all patients after anticoagulant therapy was discontinued; 4) a blind review and validation of all outcomes by an independent centralised adjudication committee; 5) a central assessment of PVOI and RVD by independent physicians blinded from the study treatment allocation, the results of other imaging tests and the patients' characteristics; and 6) consistency of results across main, secondary and sensitivity analyses. 
Our study has the following limitations. First, the sample size was too small to evaluate the impact of potential important predictors, such as sex, chronic inflammatory disease, residual DVT or protein C, protein $\mathrm{S}$ and antithrombin deficiencies. Second, unlike the data obtained for PVOI at inclusion, data collection for the measurement of PVOI at pulmonary embolism diagnosis was retrospective and not exhaustive. However, all available CTPAs and V/Q lung scans were interpreted by independent physicians blinded from study treatment allocation and the impact of PVOIs on the risk of recurrent VTE was consistent across all statistical models.

\section{Conclusions}

Among patients with a first episode of unprovoked pulmonary embolism, age, PVOI measured either at diagnosis or at 6 months of anticoagulation and APLAs were found to be independent predictors of recurrent VTE. Scores combining these variables identified patients at low risk of recurrent VTE in one-fifth of cases and patients at a particular high risk in one-third of cases. Validation in independent cohorts and comparison with existing rules are needed.

\section{Acknowledgements}

Members of the PADIS-PE Study Group (all in France) were as follows. Steering Committee: F. Couturaud (Chair), P. Mismetti, C. Leroyer, G. Meyer, O. Sanchez, P. Jego, G. Pernod, E. Duhamel, K. Provost, F. Parent, L. Bertoletti, C. Tromeur, D. Mottier; Coordinating Committee: F. Couturaud (Chair), M. Guégan, S. Mélac, A. Le Hir; Independent Central Adjudication Committee (Critical Events): P. Girard (Chair), S. Lenoir, C. Lamer; Data Safety Monitoring Board: J.F. Bergmann (Chair), D. Wahl, L. Drouet; statistical analysis: E. Presles, S. Laporte; data management (ClinInfo, Lyon): P. Chevarier, N. Monte; operation team (Brest University Hospital): F. Morvan, V. Kouassi, N. Ibrir, G. El Asri; lung scintigraphy panel: P.Y. Salaun, P. Robin, P.Y. Le Roux; ultrasound panel: L. Bressollette, P. Quéhé, S. Gestin; computed tomography scan panel: M. Nonent, J. Bahuon, L. Deloire, C. Tromeur, B. Planquette; echocardiography panel: Y. Jobic, Y. Etienne, R. Didier, F. Leven; central laboratory: L. Leroux, H. Galinat, C. Le maréchal, L. Gourhant, F. Mingant; investigators (by city and in order of the number of patients enrolled): Brest (198 patients): F. Couturaud, C. Leroyer, C. Tromeur, F. Leven, K. Lacut, E. Lemoigne, L. De Saint Martin, A. Delluc, G. Le Gal, N. Paleiron, R. Le Mao, D. Mottier; Paris (53 patients): O. Sanchez, G. Meyer, B. Planquette; Grenoble (33 patients) G. Pernod, C. Pison; Rennes (33 patients): P. Jego, P. Guéret; Saint-Étienne (21 patients): P. Mismetti, H. Décousus, C. Lassagne, L. Bertoletti; Saint-Brieuc (nine patients): E. Duhamel; Lannion (eight patients): K. Provost; Le Kremlin-Bicêtre (five patients): F. Parent; Quimper (three patients): B. Pan-Petesh; Toulouse (two patients): A. Bura-Riviere; Tours (two patients): B. Delahousse, Y. Gruel; Paris (two patients): C. Lorut; Clermont-Ferrand (one patient): J. Schmidt; Nantes (one patient): J. Connault.

Author contributions: F. Couturaud had full access to all of the data in the study, and takes responsibility for the integrity of the data and the accuracy of the data analysis. Study concept and design: F. Couturaud, C. Tromeur, O. Sanchez, L. Bertoletti, P. Mismetti, D. Mottier, C. Leroyer. Acquisition of data: S. Mélac. Statistical analysis: S. Laporte, E. Presles, F. Couturaud. Analysis and interpretation of data: all. Drafting of the manuscript: F. Couturaud, C. Tromeur, O. Sanchez, G. Meyer, L. Bertoletti, S. Laporte, P. Girard, E. Presles, C. Leroyer. Critical revision of the manuscript for important intellectual content: all. Final approval of the manuscript: all. Obtaining funding: F. Couturaud. Administrative, technical or material support: F. Couturaud, K. Lacut, P-Y. Salaun, L. Bressollette, M. Nonent, C. Leroyer. Study supervision: F. Couturaud.

\section{References}

1 Agnelli G, Prandoni P, Santamaria MG, et al. Three months versus one year of oral anticoagulant therapy for idiopathic deep venous thrombosis. Warfarin Optimal Duration Italian Trial Investigators. N Engl J Med 2001; 345: $165-169$.

2 Couturaud F, Sanchez O, Pernod G, et al. Six months vs extended oral anticoagulation after a first episode of pulmonary embolism: the PADIS-PE randomized clinical trial. JAMA 2015; 314: 31-40.

3 Kearon C, Akl EA, Ornelas J, et al. Antithrombotic therapy for VTE disease: CHEST guideline and expert panel report. Chest 2016; 149: 315-352.

4 Konstantinides SV, Torbicki A, Agnelli G, et al. 2014 ESC guidelines on the diagnosis and management of acute pulmonary embolism. Eur Heart J 2014; 35: 3033-3069.

5 Prandoni P, Noventa F, Ghirarduzzi A, et al. The risk of recurrent venous thromboembolism after discontinuing anticoagulation in patients with acute proximal deep vein thrombosis or pulmonary embolism. A prospective cohort study in 1,626 patients. Haematologica 2007; 92: 199-205.

6 Lecumberri R, Alfonso A, Jiménez D, et al. Dynamics of case-fatality rates of recurrent thromboembolism and major bleeding in patients treated for venous thromboembolism. Thromb Haemost 2013; 110: 834-843.

7 Linkins LA, Choi PT, Douketis JD. Clinical impact of bleeding in patients taking oral anticoagulant therapy for venous thromboembolism: a meta-analysis. Ann Intern Med 2003; 139: 893-900.

8 Rodger MA, Le Gal G, Anderson DR, et al. Validating the HERDOO2 rule to guide treatment duration for women with unprovoked venous thrombosis: multinational prospective cohort management study. BMJ 2017; 356: j1065.

9 McRae S, Tran H, Schulman S, et al. Effect of patient's sex on risk of recurrent venous thromboembolism: a meta-analysis. Lancet 2006; 368: 371-378.

10 Palareti G, Cosmi B, Legnani C, et al. D-dimer testing to determine the duration of anticoagulation therapy. N Engl J Med 2006; 355: 1780-1789.

11 Kearon C, Spencer FA, O'Keeffe D, et al. D-dimer testing to select patients with a first unprovoked venous thromboembolism who can stop anticoagulant therapy: a cohort study. Ann Intern Med 2015; 162: 27-34. 
12 Carrier M, Rodger MA, Wells PS, et al. Residual vein obstruction to predict the risk of recurrent venous thromboembolism in patients with deep vein thrombosis: a systematic review and meta-analysis. J Thromb Haemost 2011; 9: 1119-1125.

13 Segal JB, Brotman DJ, Necochea AJ, et al. Predictive value of factor V Leiden and prothrombin G20210A in adults with venous thromboembolism and in family members of those with a mutation: a systematic review. JAMA 2009; 301: 2472-2485.

14 Di Minno MN, Ambrosino P, Ageno W, et al. Natural anticoagulants deficiency and the risk of venous thromboembolism: a meta-analysis of observational studies. Thromb Res 2015; 135: 923-932.

15 Garcia D, Akl EA, Carr R, et al. Antiphospholipid antibodies and the risk of recurrence after a first episode of venous thromboembolism: a systematic review. Blood 2013; 122: 817-824.

16 Heit JA, Mohr DN, Silverstein MD, et al. Predictors of recurrence after deep vein thrombosis and pulmonary embolism: a population-based cohort study. Arch Intern Med 2000; 160: 761-768.

17 Planquette B, Ferré A, Péron J, et al. Residual pulmonary vascular obstruction and recurrence after acute pulmonary embolism. A single center cohort study. Thromb Res 2016; 148: 70-75.

18 Douketis JD, Kearon C, Bates S, et al. Risk of fatal pulmonary embolism in patients with treated venous thromboembolism. JAMA 1998; 279: 458-462.

19 Tapson VF. Acute pulmonary embolism. N Engl J Med 2008; 358: 1037-1052.

20 Kearon C, Julian JA, Newman TE, et al. Noninvasive diagnosis of deep venous thrombosis. McMaster Diagnostic Imaging Practice Guidelines Initiative. Ann Intern Med. 1998; 128: 663-677.

21 Meyer G, Vicaut E, Danays T, et al. Fibrinolysis for patients with intermediate-risk pulmonary embolism. $N$ Engl Med 2014; 370: 1402-1411.

22 Miller GA, Sutton GC, Kerr IH, et al. Comparison of streptokinase and heparin in treatment of isolated acute massive pulmonary embolism. Br Med J 1971; 2: 681-684.

23 Meyer G, Collignon MA, Guinet F, et al. Comparison of perfusion lung scanning and angiography in the estimation of vascular obstruction in acute pulmonary embolism. Eur J Nucl Med 1990; 17: 315-319.

24 Qanadli SD, El Hajjam M, Vieillard-Baron A, et al. New CT index to quantify arterial obstruction in pulmonary embolism: comparison with angiographic index and echocardiography. AJR Am J Roentgenol 2001; 176: 1415-1420.

25 Prandoni P, Lensing AW, Prins MH, et al. Residual venous thrombosis as a predictive factor of recurrent venous thromboembolism. Ann Intern Med 2002; 137: 955-960.

26 Harrell FE, Lee KL, Mark DB. Multivariable prognostic models: issues in developing models, evaluating assumptions and adequacy, and measuring and reducing errors. Stat Med 1996; 15: 361-387.

27 Poli D, Cenci C, Antonucci E, et al. Risk of recurrence in patients with pulmonary embolism: predictive role of D-dimer and of residual perfusion defects on lung scintigraphy. Thromb Haemost 2013; 109: 181-186.

28 Wartski M, Collignon MA. Incomplete recovery of lung perfusion after 3 months in patients with acute pulmonary embolism treated with antithrombotic agents. J Nucl Med 2000; 41: 1043-1048.

29 Nijkeuter M, Hovens MM, Davidson BL, et al. Resolution of thromboemboli in patients with acute pulmonary embolism: a systematic review. Chest 2006; 129: 192-197.

30 Sanchez O, Helley D, Couchon S, et al. Perfusion defects after pulmonary embolism: risk factors and clinical significance. J Thromb Haemost 2010; 8: 1248-1255.

31 Pesavento R, Filippi L, Palla A, et al. Impact of residual pulmonary obstruction on the long-term outcome of patients with pulmonary embolism. Eur Respir J 2017; 49: 1601980.

32 den Exter PL, van Es J, Kroft LJM, et al. Thromboembolic resolution assessed by CT pulmonary angiography after treatment for acute pulmonary embolism. Thromb Haemost 2015; 114: 26-34.

33 van Es J, Douma RA, Kamphuisen PW, et al. Clot resolution after 3 weeks of anticoagulant treatment for pulmonary embolism: comparison of computed tomography and perfusion scintigraphy. J Thromb Haemost 2013; 11: 679-685.

34 Gottschalk A, Sostman HD, Coleman RE, et al. Ventilation-perfusion scintigraphy in the PIOPED study. Part II. Evaluation of the scintigraphic criteria and interpretations. J Nucl Med 1993; 34: 1119-1126.

35 Meneveau N, Ider O, Seronde MF, et al. Long-term prognostic value of residual pulmonary vascular obstruction at discharge in patients with intermediate- to high-risk pulmonary embolism. Eur Heart J 2013; 34: 693-701.

36 van der Meer RW, Pattynama PM, van Strijen MJ, et al. Right ventricular dysfunction and pulmonary obstruction index at helical CT: prediction of clinical outcome during 3-month follow-up in patients with acute pulmonary embolism. Radiology 2005; 235: 798-803.

37 Miniati M, Monti S, Bottai M, et al. Survival and restoration of pulmonary perfusion in a long-term follow-up of patients after acute pulmonary embolism. Medicine 2006; 85: 253-262.

38 Marcucci M, Iorio A, Douketis JD, et al. Risk of recurrence after a first unprovoked venous thromboembolism: external validation of the Vienna Prediction Model with pooled individual patient data. J Thromb Haemost 2015; 13: $775-781$.

39 Tosetto A, Testa S, Martinelli I, et al. External validation of the DASH prediction rule: a retrospective cohort study. J Thromb Haemost 2017; 15: 1963-1970. 